\title{
A novel membrane distillation - thermophilic bioreactor system: \\ Biological stability and trace organic compound removal
}

\author{
Revised manuscript submitted to
}

\section{Bioresource Technology}

Feb 2014

Kaushalya C. Wijekoon ${ }^{\text {a }}$, Faisal I. Hai ${ }^{\text {a }}$, Jinguo Kang ${ }^{\mathrm{b}}$, William E. Price ${ }^{\mathrm{b}}$, Wenshan Guo ${ }^{\text {c }}$, Hao H. Ngo ${ }^{\text {c }}$, Tzahi Y. Cath ${ }^{\text {d, }}$ Long D. Nghiem ${ }^{\text {a,* }}$

${ }^{a}$ Strategic Water Infrastructure Laboratory, School of Civil Mining and Environmental Engineering, University of Wollongong, Wollongong, NSW 2522, Australia

${ }^{\mathrm{b}}$ Strategic Water Infrastructure Laboratory, School of Chemistry University of Wollongong, Wollongong, NSW 2522, Australia

c Centre for Technologies in Water and Wastewater,

School of Civil and Environmental Engineering, University of Technology Sydney, Sydney NSW 2007, Australia

d Advanced Water Technology Center (AQWATEC), Department of Civil and Environmental Engineering, Colorado School of Mines, Golden, CO 80401, USA

\footnotetext{
* Corresponding author: Long Duc Nghiem, Email: longn@uow.edu.au; Ph +61 242214590
} 


\begin{abstract}
The removal of trace organic compounds (TrOCs) by a novel membrane distillation thermophilic bioreactor (MDBR) system was examined. Salinity build-up and the thermophilic conditions to some extent adversely impacted the performance of the bioreactor, particularly the removal of total nitrogen and recalcitrant TrOCs. While most TrOCs were well removed by the thermophilic bioreactor, compounds containing electron withdrawing functional groups in their molecular structure were recalcitrant to biological treatment and their removal efficiency by the thermophilic bioreactor were low (0 to 53\%). However, the overall performance of the novel MDBR system with respect to the removal of total organic carbon, total nitrogen, and TrOCs was high and was not significantly affected by the conditions of the bioreactor. All TrOCs investigated here were highly removed $(>95 \%)$ by the MDBR system. Biodegradation, sludge adsorption, and rejection by MD contribute to the removal of TrOCs by MDBR treatment.
\end{abstract}

Keywords: Membrane distillation, thermophilic bioreactor, salinity build-up, biodegradation/transformation, adsorption, trace organic compounds (TrOCs). 


\section{Introduction}

Water reclamation is a pragmatic approach to address the scarcity of water supplies in urban areas due to population growth and irregular climate pattern (Shannon et al., 2008). Through water reclamation, municipal wastewater can be a reliable alternative source for clean water supply. However, development of advanced treatment processes is necessary to ensure a uate removal of common contaminants (e.g., organics, nutrients, minerals) and especially rar organic compounds (TrOCs) that occur ubiquitously in municipal wastewater. The TrOCs include steroid hormones, pharmaceuticals, personal care products, surfacts ms, py ticides, disinfection by-products, and UV filters (Tran et al., 2013b; Zhao et al, 2 (10) hat have been widely detected in raw sewage and reclaimed effluent from convent all vastewater treatment plants. Their occurrence is of major health and environmental conc $\mathrm{n}$ because of their potential adverse impact on living organisms (Schwarzenbach et al., 2 9). Thus, the removal of TrOCs during water reclamation has been the subject of intensive search in recent years.

Membrane bioreactor (MBR) is an efficient was wa r treatment technology, capable of producing reuse standard affluent (Melin et Do). MBRs can effectively remove TrOCs that are hydrophobic and/or readily biodegradable (Boonyaroj et al., 2012; Clara et al., 2005; Tadkaew et al., 2011; Tran et al., 20 a a); lowever, recent studies have highlighted the challenges of removing recalci an T OCs (e.g., carbamazepine, diclofenac, etc.) by biological based treatment processes cluding MBRs (Clara et al., 2005; Radjenović et al., 2009; Tadkaew et al., 2011; Wijekoon ct 1., 2013b).

Tadkaew et al., $(201$ ) suggested that biodegradability of a TrOC can be qualitatively assessed based on the presc ve of electron donating functional groups (EDGs) or electron withdrawing functional or (EWGs) in their molecules. They demonstrated that TrOCs with EDGs can be well (mo ed in an MBR, whereas TrOCs with EWGs (such as chloride and amide) in their 1vo wre are usually poorly removed by MBRs. In a subsequent study, Wijekoon et al., (2013b) S cicessfully extended this framework to elucidate the fate of TrOCs in the aqueous and sludge phases during MBR treatment. Given the resistance of some TrOCs to biodegradation, the use of post-treatment processes to specifically target these recalcitrant TrOCs has also been explored. Examples of these post-treatment processes subsequent to MBR treatment include reverse 
osmosis (Alturki et al., 2010), activated carbon adsorption (Nguyen et al., 2013a), and ultraviolet oxidation (Nguyen et al., 2013b).

Integration of a high retention membrane process such as nanofiltration (Choi et al., 2002), forward osmosis (Achilli et al., 2009; Alturki et al., 2012; Hancock et al., 2013), or membra distillation (MD) (Goh et al., 2013a; Goh et al., 2013b; Khaing et al., 2010; Phattaranaw 2009) with a bioreactor constitutes a so called high retention MBR, which can be an fit means to achieve high removal of pollutants. The working principles of these in eg ated processes have been demonstrated in recent studies; however, except for Al al al., (2012) and Hancock et al., (2011), the removal of TrOCs using these novel high ton MBRs has not been investigated.

MD is a low temperature distillation process that involves the ans ort of water vapour from a feed solution through the pores of a microporous and hyduan bic membrane to the distillate (product) side. Because mass transfer occurs in a gaoms purase, MD offers complete rejection of all non-volatile solutes (Curcio and Drioli, 2005 Ma pbrane distillation bioreactor (MDBR) is a high retention MBR process where MD mer can act as a barrier against the permeation of low molecular weight compounds and recalcitrant compounds. In the MDBR process, the biological reactor can be operated ar herr ophilic conditions to facilitate the integration of biological treatment with MD. d dision, the thermophilic bioreactor can also result in enhanced biodegradation o rgan cs and low sludge yield (LaPara and Alleman, 1999). 
immersion heating unit (Julabo, Germany) to keep the temperature at $40 \pm 0.1{ }^{\circ} \mathrm{C}$. It was also covered with aluminium foil to avoid any exposure to sunlight and heat loss. The bioreactor was aerated using an air pump (Risheng RS 9801, China) connected to a glass diffuser, and an overhead mixer (Heidolph Instruments, Germany) was used to maintain homogeneity within the bioreactor. The mixed liquor of the bioreactor was used as the feed to the external DCMD module.

\section{[FIGURE 1]}

The DCMD module was made of acrylic glass to minimize heat loss to the surroundings. The flow channels were engraved in each of two acrylic glass blocks that made up the feed and distillate semi-cells. The length, width, and height of each channel were 145, 95, and $3 \mathrm{~mm}$, respectively. The total active membrane surface area for mass transfer was $140 \mathrm{~cm}^{2}$. Feed to the MD system (mixed liquor from the bioreactor) was continuously pumped to the membrane cell and recirculated back to the bioreactor. The temperature of the feed solution entering the MD cell was monitored using a temperature sensor connected to the feed line immediately outside the inlet. The temperature of the distillate leaving the membrane cell was monitored using another temperature sensor located immediately after the outlet of the distillate semi-cell. The temperature of the distillate was kept at $14.0 \pm 0.1^{\circ} \mathrm{C}$ using a chiller (Neslab RTE7, Thermo Scientific, USA) equipped with a stainless steel heat exchanging coil, which was directly immersed in the distillate reservoir. A glass container was used as the distillate reservoir and was placed on a digital balance (Mettler Toledo Inc, USA) to calculate the distillate flux. Excess distillate was pumped out from the distillate reservoir intermittently and collected in a stainless steel container for analysis. The MD feed and distillate flow rate were monitored using two rotameters and maintained at $1 \mathrm{~L} / \mathrm{min}$ (corresponding to a cross flow velocity of $9 \mathrm{~cm} / \mathrm{s}$ ). Milli-Q water $(2.25 \mathrm{~L})$ was used as the initial distillate. The MDBR system was covered with insulation foam to minimize heat loss. A hydrophobic microporous polytetrafloroethylene (PTFE) membrane (GE, Minnetonka, MN) was used. The average pore size, porosity, thickness and active layer thickness of this membrane were $0.22 \mu \mathrm{m}, 70 \%, 175 \mu \mathrm{m}$ and $5 \mu \mathrm{m}$, respectively (Nghiem and Cath, 2011). 


\subsection{Experimental protocol}

The bioreactor system was inoculated with activated sludge from the Wollongong Wastewater Treatment Plant (Wollongong, Australia). A synthetic wastewater was used to simulate medium strength domestic wastewater and to maintain stable operating conditions. The synthetic wastewater was prepared daily by diluting a concentrated stock with Milli-Q water to obtain 100 $\mathrm{mg} / \mathrm{L}$ glucose, $100 \mathrm{mg} / \mathrm{L}$ peptone, $17.5 \mathrm{mg} / \mathrm{L} \mathrm{KH}_{2} \mathrm{PO}_{4}, 17.5 \mathrm{mg} / \mathrm{L} \mathrm{MgSO}_{4}, 10 \mathrm{mg} / \mathrm{LFeSO}_{4}, 225$ $\mathrm{mg} / \mathrm{L} \mathrm{CH}_{3} \mathrm{COONa}$ and $35 \mathrm{mg} / \mathrm{L}$ urea (Alturki et al., 2012). The concentrated stock solution was prepared every week and kept at $4{ }^{\circ} \mathrm{C}$ in the dark.

Prior to the MDBR experiment, the bioreactor was acclimatised at $40{ }^{\circ} \mathrm{C}$ by operating the system in an MBR mode using a ceramic microfiltration membrane module (NGK, Japan). During the acclimatisation period, the bioreactor was operated at a hydraulic retention time (HRT) of $24 \mathrm{~h}$ and a solids retention time (SRT) of $88 \mathrm{~d}$. The temperature, dissolved oxygen (DO) concentration and conductivity of the mixed liquor were $40{ }^{\circ} \mathrm{C}, 2.8 \pm 0.5 \mathrm{mg} / \mathrm{L}$, and $425 \mu \mathrm{S} / \mathrm{cm}$, respectively. The mixed liquor suspended solids (MLSS) concentration was $5.3 \mathrm{~g} / \mathrm{L}$, and under these operating conditions the mixed liquor $\mathrm{pH}$ remained stable at 7.6. More details about the ceramic MBR system are available elsewhere (Wijekoon et al., 2013b). After the bioreactor had been acclimatised for $75 \mathrm{~d}$, the ceramic microfiltration membrane module was removed and the bioreactor was connected to the DCMD system. TrOCs were then continuously introduced to the influent at a concentration of approximately $5 \mu \mathrm{g} / \mathrm{L}$ of each compound. MDBR operation was initiated at temperature and DO concentration of $40{ }^{\circ} \mathrm{C}$ and $2.8 \pm 0.5 \mathrm{mg} / \mathrm{L}$, respectively, and operated for $38 \mathrm{~d}$. The HRT of the MDBR was $9.6 \mathrm{~d}$ due to the low distillate flux of the DCMD system. The basic biological performance of the MDBR in terms of total organic carbon (TOC) and total nitrogen (TN) removal, conductivity/pH variation, and MLSS concentration was continuously monitored. The mixed liquor was collected weekly and centrifuged at $3270 \mathrm{xg}$ for 10 min (Alleegra X-12R, Beckman Coulter, USA) to obtain the supernatant and sludge pellets for further analysis. Feed and distillate samples were collected for TrOC analysis on a weekly basis. The concentration of TrOCs in the distillate was calculated by taking into account the volume of Milli-Q water (2.25 L) used as the initial make up water.

TrOC removal by bioreactor $\left(\mathrm{R}_{1}\right), \mathrm{MD}\left(\mathrm{R}_{2}\right)$ and MDBR hybrid system $\left(\mathrm{R}_{\mathrm{T}}\right)$ are defined as: 


$$
\begin{aligned}
& \mathrm{R}_{1}=100 \times\left(1-\frac{\mathrm{C}_{\mathrm{Su}_{\mathrm{u}}}}{\mathrm{C}_{\mathrm{F}}}\right) \\
& \mathrm{R}_{2}=100 \times\left(1-\frac{\mathrm{C}_{\mathrm{D}}}{\mathrm{C}_{\mathrm{Su}}}\right) \\
& \mathrm{R}_{\mathrm{T}}=100 \times\left(1-\frac{\mathrm{C}_{\mathrm{D}}}{\mathrm{C}_{\mathrm{F}}}\right)
\end{aligned}
$$

where $\mathrm{C}_{\mathrm{F}}, \mathrm{C}_{\mathrm{Su}}$, and $\mathrm{C}_{\mathrm{D}}$ are concentration of the specific compound in the bioreactor feed, bioreactor supernatant, and distillate, respectively. Biodegradation/transformation of TrOCs during the treatment by the hybrid process was calculated by considering the mass balance of each compound in the feed, supernatant, sludge and distillate as given in Equation 4. 


\subsubsection{TrOC analysis}

The concentration of TrOCs in the sludge phase (mixed liquor) was determined according to a method previously described by Wijekoon et al., (2013a). The solid pellets obtained from the mixed liquor after centrifugation (Section 2.2) were freeze-dried for $4 \mathrm{~h}$ using an Alpha 1-2 LDplus Freeze Dryer (Christ GmbH, Germany). The dried sludge was ground to powder and 0.5 g powder was transferred to a glass test tube for extraction. Methanol $(5 \mathrm{~mL})$ was added to the test tube, thoroughly mixed using a vortex mixer (VM1, Ratek, Australia) for $3 \mathrm{~min}$, and ultrasonicated for $10 \mathrm{~min}$ at $40{ }^{\circ} \mathrm{C}$. The sample was centrifuged at $3270 \mathrm{xg}$ for $10 \mathrm{~min}$ (Alleegra $\mathrm{X}-12 \mathrm{R}$, Beckman Coulter, USA) and the supernatant was collected in a glass beaker for further analysis. Dichloromethane $(5 \mathrm{~mL})$ and methanol $(5 \mathrm{~mL})$ were added to the remaining sludge, and the process of mixing, ultrasonic extraction, and centrifugation was repeated. The supernatants from both steps were combined, Milli-Q water added up to a volume $50 \mathrm{~mL}$, and the residual methanol and dichloromethane were purged using nitrogen gas. Finally, Milli-Q water was added to obtain a $500 \mathrm{~mL}$ aqueous sample. This sample was then analysed using the analytical method described below, and TrOC concentrations per gram of dry sludge were calculated.

TrOC concentrations in the aqueous phase were determined using a method previously reported by Hai et al., (2011b). This method consists of a solid phase extraction procedure followed by gas chromatography and quantitative determination by mass spectrometry with electron ionization. TrOC concentrations in liquid samples (500 mL each) were extracted using $6 \mathrm{~mL} 200$ mg Oasis HLB cartridges (Waters, Milford, MA, USA). First, the cartridges were preconditioned with $7 \mathrm{~mL}$ dichloromethane and methanol mixture $(1: 1 \mathrm{v} / \mathrm{v}), 7 \mathrm{~mL}$ methanol, followed by $7 \mathrm{~mL}$ reagent water (synthetic feed wastewater excluding TrOCs). The samples were acidified to $\mathrm{pH} 2$ 3 and loaded onto the cartridges at a flow rate of $1-5 \mathrm{~mL} / \mathrm{min}$. Then, the cartridges were rinsed with $20 \mathrm{~mL}$ Milli-Q water and dried in a stream of nitrogen gas for $30 \mathrm{~min}$. The extracted TrOCs were eluted from the cartridge using $7 \mathrm{~mL}$ of methanol followed by dichloromethane and methanol mixture $(1: 1 \mathrm{v} / \mathrm{v})$ at a flow rate of $1-5 \mathrm{~mL} / \mathrm{min}$. Then the eluents were evaporated in a water bath $\left(40{ }^{\circ} \mathrm{C}\right)$ under a gentle stream of nitrogen. The extracts were dissolved in $200 \mu \mathrm{L}$ methanol which contained $5 \mu \mathrm{g}$ bisphenol A- $\mathrm{d}_{16}$, transferred into $1.5 \mathrm{~mL}$ vials, and further evaporated under a gentle stream of nitrogen. Finally, the extracts were derivatized by adding $100 \mu \mathrm{L}$ of N,O-Bis(trimethylsilyl)trifluoroacetamide (1\% trimethylchlorosilane) and pyridine (dried with $\mathrm{KOH}$ solid), then heated in a heating block $\left(60-70{ }^{\circ} \mathrm{C}\right.$ ) for $30 \mathrm{~min}$. The derivatives 
were cooled to room temperature and analysed using a GC-MS QP5000 (Shimadzu, Japan) unit equipped with an AOC20i autosampler and a Phenomenex Zebron ZB-5 (5\% diphenyl-95\% dimethylpolysiloxane) capillary column $\left(30 \mathrm{~m} \times 0.25 \mathrm{~mm} \mathrm{ID,} \mathrm{d}_{\mathrm{f}}=0.25 \mu \mathrm{m}\right)$. The limit of detection of the selected TrOCs by this analytical method was $20 \mathrm{ng} / \mathrm{L}$ or lower (Hai et al., 2011b).

\section{Results and discussion}

\subsection{Biological Performance}

Basic performance of both the thermophilic bioreactor and MDBR system were assessed in terms of the distillate flux, distillate quality (i.e., conductivity, TOC, and TN), sludge characteristics (i.e., DO concentration, conductivity, $\mathrm{pH}, \mathrm{MLSS}$, and MLVSS) and organics removal (i.e., TOC and TN). The main performance parameters of the system are summarised in Fig. 2. Water flux through the MD membrane decreased from 4 to about $2 \mathrm{~L} / \mathrm{m}^{2} . \mathrm{h}$ within the first three days of operation, and after about 10 days of operation it became stable at approximately $1.2 \pm 0.2 \mathrm{~L} / \mathrm{m}^{2} . \mathrm{h}$ (Fig. 2a). This observed flux profile was consistent with several previous studies (Khaing et al., 2010; Phattaranawik et al., 2008; Phattaranawik et al., 2009). The low water flux observed here could be attributed to the low cross flow velocity (i.e., $9 \mathrm{~cm} / \mathrm{s}$; see Section 2.1) in the MD cell used in a laboratory scale system and can be improved by increasing the circulation flow rate. In addition, the stable water flux after 10 days of operation indicated that membrane wetting did not occur in this study, which was also evidenced by the low conductivity $(<5$ $\mu \mathrm{S} / \mathrm{cm}$ ) of the distillate (Fig. 2b) during the entire experiment. Changes in hydrophobicity as a result of membrane wetting would lead to lower distillate quality (or an increase in distillate conductivity).

\section{[FIGURE 2]}

The mixed liquor salinity (measured by conductivity) increased continuously as the MDBR experiment progressed (Fig. 2b). It is noteworthy that the occasional slight drop in the mixed liquor salinity (Fig. 2b) was due to the collection of supernatant for sampling and replenishment with low salinity makeup wastewater. Salinity build-up during MDBR operation was attributed to the complete rejection of salts by MD (Gryta et al., 2006; Khaing et al., 2010; Phattaranawik et al., 2009). Moreover, there was a small increase in $\mathrm{pH}$ of the mixed liquor from 7.6 to 8.2, 
which was possibly due to the stripping of carbon dioxide at thermophilic temperatures (Goh et al., 2013a; Suzuki et al., 2002).

TOC removal by the thermophilic bioreactor was stable at 94\%, and the supernatant TOC was always below 14 mg/L (Fig. 3a). In addition, TOC removals by thermophilic bioreactor befo (Supplementary Data, Fig. S1a) and after MDBR experiment were almost identical. As at of the heterotrophic bacteria are subspecies of the halophilic and halotolerent microbia on nunity, heterotrophic bacteria are more tolerant to salinity increase. Thus, the impact of a hity increase on TOC removal was insignificant (Lay et al., 2010). However, TN removary thermophilic bioreactor significantly decreased from relatively stable removal at $51 \%$ to MDBR experiment) to almost zero after only about four days of integration 6 bioreactor with the MD unit (Fig. 3b and Supplementary Data, Fig. S1b). The poocren, val of TN probably resulted from the increase of the mixed liquor salinity which is toxic n nitrifying bacteria (Lay et al., 2010). LaPara and Alleman (1999) also reported that ther sphilic aerobic biological treatment is more susceptible to environmental changes than a $m$ ophilic process. A gradual reduction in bioreactor MLVSS concentration was notice at tarting MDBR experiment (Supplementary Data, Fig. S2 and Fig. S3), and this can be attn. uted to salinity build-up as reported by Alturki et al., (2012) who explored a bioreacto nte ated with a forward osmosis unit. This is also consistent with the reported low sly geyield by thermophilic aerobic biological treatment (LaPara and Alleman, 1999)

Although the thermop 17 conditions could exert some negative effects on the performance of the bioreactor whic saly builds up, the overall TOC (>99\%) and TN (>96\%) removals by the hybrid MDBR_sy a were high and independent of the biological stability of the reactor. Distillate $6 \mathrm{C}$ h TN concentrations were below $1 \mathrm{mg} / \mathrm{L}$ throughout the experiment. These resul cor irmed that the high performance of MD can offset the negative impact on the biological treatment to produce high quality effluent.

[FIGURE 3]

\subsection{TrOC removal}

[FIGURE 4] 
Biological removal in the thermophilic bioreactor and rejection by the MD membrane are the two removal mechanisms of TrOCs in the MDBR system. The individual and total removals of the investigated TrOCs are depicted in Fig. 4. Most TrOCs were moderately or highly removed during thermophilic biological treatment. The results observed showed that salinity build-up $d$ not significantly affect the removal of readily biodegradable TrOCs, and their removal efficiencies were stable over the entire experimental period (Supplementary Data, Fig. 1. The reason might be that biodegradation of these TrOCs was mainly driven by heterg phy bacteria, which are tolerant to salinity changes (Lay et al., 2010). All TrOCs containing $\mathbf{G s}$ (Supplementary Data, Fig.S5) in their molecules (i.e., clofibric acid, feno rop. Aiclofenac, carbamazepine, atrazine, and triclosan) were poorly removed by the tical process in the thermophilic bioreactor, and the removal efficiency was in the rant or zero to $53 \%$. Moreover, removal efficiency of carbamazepine, atrazine, and triclosar collally deteriorated with time (Supplementary Data, Fig. S4), exhibiting the detrimenta. Firect of salinity build-up on the removal of recalcitrant TrOCs by the bioreactor alor $>$ notable that despite being a hydrophobic compound, triclosan removal by th ipleactor was remarkably low (53\%) compared to the values previously reported it. arse of conventional MBR treatment (Hai et al., 2011b; Miège et al., 2009; Tadkaew edr. 2011). The bioreactor removal efficiency of carbamazepine in this study was so s, Aficantly lower than that by a thermophilic MBR operated at similar temperatuse n ned by Hai et al., (2011b) and Wijekoon et al., (2013c). The complexity associated with th. dynamic salinity level could modify the microbial community of MDBR due to the sa sitection where nitrification is highly susceptible to the salinity changes (Lay et 1,2010). As carbamazepine is a nitrogenous compound and more likely to be removed by ntrify.ng bacteria (Hai et al., 2011 a; Wijekoon et al., 2013b), it was substantially affected by salinity increase in the bioreactor. It is noteworthy that this study was conducted over she $t$ period. In long term operation of the MDBR, the impact of salinity build-up may 9 less critical due to selective microbial growth and natural adaptation of the halophilic bucteria (Lay et al., 2010).

All TrOCs investigated in this study were well removed (>95\%) by the integrated MDBR system (Fig. 4) despite the impact of salinity build-up on recalcitrant TrOC removal by the bioreactor. TrOC removal by the MD process was investigated in a previous study (Wijekoon et al., 2013c). Although TrOCs with low volatility $\left(\mathrm{pK}_{\mathrm{H}}>9\right)$ were well rejected, $\mathrm{MD}$ alone was not effective for 
removal of TrOCs (such as 4-tert-butyl phenol and oxybenzonethat) which are moderately volatile $\left(\mathrm{pK}_{\mathrm{H}}<9\right)$ (Wijekoon et al., 2013c). Thus, the results in the current study imply that MD can complement the biological treatment process very well to achieve high TrOC removal. In addition, the novel MDBR system may offer a high effluent quality independent of the operating conditions of the bioreactor.

\subsection{Fate and distribution of TrOCs during the MDBR process}

[FIGURE 5]

The concentrations of TrOCs and their associated $\log \mathrm{D}$ and $\mathrm{pK}_{\mathrm{H}}$ values in the solid and liquid phases of the different streams of the MDBR are summarised in Fig. 5. The concentrations of most TrOCs in the aqueous (i.e., feed to the bioreactor, supernatant, and distillate) and solid phases were stable during the experiment. The accumulation of certain TrOCs in the supernatant (Supplementary Data, Fig. S6) may be ascribed to their low biological removal as discussed above. Triclosan was the only TrOC that significantly accumulated in the sludge phase because it is a hydrophobic $\left(\log D_{\mathrm{pH} 8}=4.92\right)$ and recalcitrant compound.

Biodegradation/transformation by the thermophilic bioreactor, adsorption to the sludge phase, and rejection by the MD membrane could all contribute to the removal of TrOCs by the MDBR system. The mass balance of each TrOC was calculated (Equations 1-4) based on the loading in the feed, supernatant, sludge, and distillate in order to determine the relative contribution between biodegradation/transformation, accumulation in supernatant, adsorption to sludge and volatilisation during MDBR treatment. Volatilisation during the MD process was calculated by taking into account the compound concentration in the distillate. Finally, the percentage of biodegradation/transformation was determined from the difference of measured concentrations in the feed, the bioreactor supernatant, and the distillate (Fig.6).

Percentage biodegradation/transformation, adsorption to sludge, and rejection by MD (accumulation in the supernatant) of TrOCs during MDBR treatment are reported in Fig. 6. Volatilisation to the distillate was insignificant considering the low volatility (as denoted by low Henry's constant or high $\mathrm{pK}_{\mathrm{H}}$ ) and negligible distillate concentrations of all TrOCs investigated (Fig. 5). The hydrophobicity (measured by $\log D$ ) and the presence of EDGs and EWGs could also govern the fate and transport of TrOCs. Results revealed that readily biodegradable TrOCs 
were mainly removed by biodegradation $(>70 \%)$. As noted earlier, biodegradation of recalcitrant TrOCs (possessing only EWGs) was considerably low compared to their removal by a conventional MBR process as previously reported (Hai et al., 2011b; Miège et al., 2009; Radjenović et al., 2009; Wijekoon et al., 2013b; Wijekoon et al., 2013c). Biodegradation of triclosan, possessing strong EWG (i.e., chloride) was low (26\%) compared to octocrylene- $4 \%$ \% which possesses weak EWGs (i.e., cyano).

TrOC rejection by MD was the main removal mechanism of recalcitrant compo an the MDBR hybrid system. MD rejection accounted for the greater portion of o a all moval of six recalcitrant TrOCs, including triclosan (42\%), fenoprop (64\%), atrazine ( 6 ) clofibric acid (71\%), diclofenac (75\%), and carbamazepine (94\%).

Accumulation in sludge greatly contributed to the aqueous pho reval of hydrophobic recalcitrant compounds (i.e., triclosan and octocrylene). accumulation in sludge was governed more by the stanoth of the EWG than the hydrophobicity of the compound. For example, sludge adsorptio of Iclosan, which is less hydrophobic ( $\log D$ pH 8 =4.92) but possesses stronger EWGs (i. ro), was higher (33\%) compared to that of octocrylene (22\%), which is more hydronhobic $\left(\log D_{\mathrm{pH}} 8=6.89\right)$ but possesses weaker EWGs (i.e., cyano).

[FIGURE 6]

\section{Conclusion}

The removal of 24 os by a novel hybrid MDBR system was investigated. While most TrOCs were well remove biological processes in the thermophilic bioreactor, compounds containing EWG grou, in their molecular structure were recalcitrant to biological degradation. Salinity build up of curred during MDBR operation which negatively affected the performance of the Tagical processes in the thermophilic bioreactor, lowering the removal of total nitrogen and $r$ valcitrant TrOCs. However, the overall performance of the MDBR system with respect to the removal of all 25 TrOCs, TOC, and TN was high and independent of the performance of the bioreactor. 


\section{Acknowledgement}

This research was supported under Australian Research Council's Discovery Projects funding scheme (project DP140103864). The authors would like to thank the University of Wollongong for the PhD scholarship support to Kaushalya C. Wijekoon.

\section{References}

[1] Achilli, A., Cath, T.Y., Marchand, E.A., Childress, A.E. 2009. The forward osmosis membrane bioreactor: A low fouling alternative to MBR processes. Desalination, 239, $10-21$.

[2] Alturki, A., McDonald, J., Khan, S.J., Hai, F.I., Price, W.E., Nghiem, L.D. 2012. Performance of a novel osmotic membrane bioreactor (OMBR) system: Flux stability and removal of trace organics. Bioresour. Technol., 113, 201-206.

[3] Alturki, A.A., Tadkaew, N., McDonald, J.A., Khan, S.J., Price, W.E., Nghiem, L.D. 2010. Combining MBR and NF/RO membrane filtration for the removal of trace organics in indirect potable water reuse applications. J Memb Sci, 365, 206-215.

[4] Boonyaroj, V., Chiemchaisri, C., Chiemchaisri, W., Theepharaksapan, S., Yamamoto, K. 2012. Toxic organic micro-pollutants removal mechanisms in long-term operated membrane bioreactor treating municipal solid waste leachate. Bioresour. Technol., 113, 174-180.

[5] Choi, J.-H., Dockko, S., Fukushi, K., Yamamoto, K. 2002. A novel application of a submerged nanofiltration membrane bioreactor (NF MBR) for wastewater treatment. Desalination, 146, 413-420.

[6] Clara, M., Strenn, B., Gans, O., Martinez, E., Kreuzinger, N., Kroiss, H. 2005. Removal of selected pharmaceuticals, fragrances and endocrine disrupting compounds in a membrane bioreactor and conventional wastewater treatment plants. Water Res., 39, 4797-4807.

[7] Curcio, E., Drioli, E. 2005. Membrane distillation and related operations-A review. Separation \& Purification Reviews, 34, 35-86.

[8] Goh, S., Zhang, J., Liu, Y., Fane, A.G. 2013a. Fouling and wetting in membrane distillation (MD) and MD-bioreactor (MDBR) for wastewater reclamation. Desalination, 323, 39-47.

[9] Goh, S., Zhang, Q., Zhang, J., McDougald, D., Krantz, W.B., Liu, Y., Fane, A.G. 2013 b. Impact of a biofouling layer on the vapor pressure driving force and performance of a membrane distillation process. J Memb Sci, 438, 140-152.

[10] Gryta, M., Tomaszewska, M., Karakulski, K. 2006. Wastewater treatment by membrane distillation. Desalination, 198, 67-73.

[11] Hai, F.I., Li, X., Price, W.E., Nghiem, L.D. 2011a. Removal of carbamazepine and sulfamethoxazole by MBR under anoxic and aerobic conditions. Bioresour. Technol., 102, 10386-10390. 
[12] Hai, F.I., Tessmer, K., Nguyen, L.N., Kang, J., Price, W.E., Nghiem, L.D. 2011b. Removal of micropollutants by membrane bioreactor under temperature variation. J Memb Sci, $383,144-151$.

[13] Hancock, N.T., Xu, P., Heil, D.M., Bellona, C., Cath, T.Y. 2011. Comprehensive Benchand Pilot-Scale Investigation of Trace Organic Compounds Rejection by Forward Osmosis. Environ Sci Technol, 45, 8483-8490.

[14] Hancock, N.T., Xu, P., Roby, M.J., Gomez, J.D., Cath, T.Y. 2013. Towards direct potable reuse with forward osmosis: Technical assessment of long-term process performance at the pilot scale. JMemb Sci, 445, 34-46.

[15] Khaing, T.-H., Li, J., Li, Y., Wai, N., Wong, F.-s. 2010. Feasibility study on petrochemical wastewater treatment and reuse using a novel submerged membrane distillation bioreactor. Separation and Purification Technology, 74, 138-143.

[16] LaPara, T.M., Alleman, J.E. 1999. Thermophilic aerobic biological wastewater treatment. Water Res., 33, 895-908.

[17] Lay, W.C.L., Liu, Y., Fane, A.G. 2010. Impacts of salinity on the performance of high retention membrane bioreactors for water reclamation: A review. Water Res., 44, 21-40.

[18] Melin, T., Jefferson, B., Bixio, D., Thoeye, C., De Wilde, W., De Koning, J., van der Graaf, J., Wintgens, T. 2006. Membrane bioreactor technology for wastewater treatment and reuse. Desalination, 187, 271-282.

[19] Miège, C., Choubert, J.M., Ribeiro, L., Eusèbe, M., Coquery, M. 2009. Fate of pharmaceuticals and personal care products in wastewater treatment plants - Conception of a database and first results. Environ. Pollut., 157, 1721-1726.

[20] Nghiem, L.D., Cath, T. 2011. A scaling mitigation approach during direct contact membrane distillation. Separation and Purification Technology, 80, 315-322.

[21] Nguyen, L.N., Hai, F.I., Kang, J., Nghiem, L.D., Price, W.E., Guo, W., Ngo, H.H., Tung, K.-L. 2013a. Comparison between sequential and simultaneous application of activated carbon with membrane bioreactor for trace organic contaminant removal. Bioresour. Technol., 130, 412-417.

[22] Nguyen, L.N., Hai, F.I., Kang, J., Price, W.E., Nghiem, L.D. 2013b. Removal of emerging trace organic contaminants by MBR-based hybrid treatment processes. International Biodeterioration \& Biodegradation, 85, 474-482.

[23] Phattaranawik, J., Fane, A.G., Pasquier, A.C.S., Bing, W. 2008. A novel membrane bioreactor based on membrane distillation. Desalination, 223, 386-395.

[24] Phattaranawik, J., Fane, A.G., Pasquier, A.C.S., Bing, W., Wong, F.S. 2009. Experimental Study and Design of a submerged membrane distillation bioreactor: Research article. Chemical Engineering Technology, 32, 38-44.

[25] Radjenović, J., Petrović, M., Barceló, D. 2009. Fate and distribution of pharmaceuticals in wastewater and sewage sludge of the conventional activated sludge (CAS) and advanced membrane bioreactor (MBR) treatment. Water Res., 43, 831-841. 
[26] Schwarzenbach, R.P., Escher, B.I., Fenner, K., Hofstetter, T.B., Johnson, C.A., von Gunten, U., Wehrli, B. 2006. The Challenge of Micropollutants in Aquatic Systems. Science, 313, 1072-1077.

[27] Shannon, M.A., Bohn, P.W., Elimelech, M., Georgiadis, J.G., Marinas, B.J., Mayes, A.M. 2008. Science and technology for water purification in the coming decades. Nature, 452, 301-310.

[28] Suzuki, K., Tanaka, Y., Osada, T., Waki, M. 2002. Removal of phosphate, magnesium and calcium from swine wastewater through crystallization enhanced by aeration. Water Res., 36, 2991-2998.

[29] Tadkaew, N., Hai, F.I., McDonald, J.A., Khan, S.J., Nghiem, L.D. 2011. Removal of trace organics by MBR treatment: The role of molecular properties. Water Res., 45, 24392451.

[30] Tran, N.H., Urase, T., Ngo, H.H., Hu, J., Ong, S.L. 2013a. Insight into metabolic and cometabolic activities of autotrophic and heterotrophic microorganisms in the biodegradation of emerging trace organic contaminants. Bioresour. Technol., 146, 721731.

[31] Tran, N.H., Urase, T., Ta, T.T. 2013b. A preliminary study on the occurrence of pharmaceutically active compounds in hospital wastewater and surface water in Hanoi, Vietnam. CLEAN - Soil, Air, Water doi:10.1002/clen.201300021.

[32] Wijekoon, K.C., Fujioka, T., McDonald, J.A., Khan, S.J., Hai, F.I., Price, W.E., Nghiem, L.D. 2013a. Removal of N-nitrosamines by an aerobic membrane bioreactor. Bioresour. Technol., 141, 41-45.

[33] Wijekoon, K.C., Hai, F.I., Kang, J., Price, W.E., Guo, W., Ngo, H.H., Nghiem, L.D. $2013 b$. The fate of pharmaceuticals, steroid hormones, phytoestrogens, UV-filters and pesticides during MBR treatment. Bioresour. Technol., 144, 247-254.

[34] Wijekoon, K.C., Hai, F.I., Kang., J., Price, W.E., Cath Tzahi , Nghiem, L.D. 2013c. Rejection and fate of trace organic compounds (TrOCs) during membrane distillation. $J$ Memb Sci doi.org/10.1016/j.memsci.2013.12.002i.

[35] Zhao, J.-L., Ying, G.-G., Liu, Y.-S., Chen, F., Yang, J.-F., Wang, L., Yang, X.-B., Stauber, J.L., Warne, M.S.J. 2010. Occurrence and a screening-level risk assessment of human pharmaceuticals in the Pearl River system, South China. Environ. Toxicol. Chem., 29, 1377-1384. 


\section{LIST OF FIGURES AND TABLES CAPTIONS}

Fig.1. Schematic diagram of the novel MDBR experimental system.

Fig. 2. (a) Distillate flux profile (b) Conductivity and $\mathrm{pH}$ variation of mixed liquor/distillate of MDBR hybrid system over the experimental period: The temperature difference across the MD cell was $24^{\circ} \mathrm{C}$ with feed temperature of $38^{\circ} \mathrm{C}$ immediately before the cell and of ate temperatures of $14{ }^{\circ} \mathrm{C}$ immediately after the cell. The conductivity and $\mathrm{pH}$ of $320 \pm 17 \mu \mathrm{S} / \mathrm{cm}$ and $7.5 \pm 0.1$, respectively. The DO concentration and temperat of bioreactor sludge were $2.8 \pm 0.5 \mathrm{mg} / \mathrm{L}$ and $40^{\circ} \mathrm{C}$, respectively.

Fig. 3. The variation of TOC and TN removal of the MDBR hybri ss $m$. The stable flux was $1.2 \pm 0.2 \mathrm{~L} / \mathrm{m}^{2}$.h. Operating conditions were as stated in the dion of Fig. 2.

Fig. 4. TrOC removal by the hybrid MDBR system. Dis, "late flux was stable at $1.2 \pm 0.2$ $\mathrm{L} / \mathrm{m}^{2}$.h. The DO concentration and temperature of the breactor sludge were $2.8 \pm 0.5 \mathrm{mg} / \mathrm{L}$ and $40{ }^{\circ} \mathrm{C}$, respectively. Removal efficiency resents the average value of duplicate samples taken once a week for five week ar ing conditions are stated in the caption of Fig. 2.

Fig. 5. Concentration of the selecto T OC in (a) the aqueous phase and (b) the sludge phase of the MDBR hybrid systen, pe ating conditions are given in Fig. 4. Error bars represent the standard deviation plicate samples taken once a week for five weeks. Error bars of sludge data represe $(t)$ standard deviation of duplicate samples taken once a week for four weeks.

Fig. 6. Fa of the selected TrOCs during MDBR treatment.

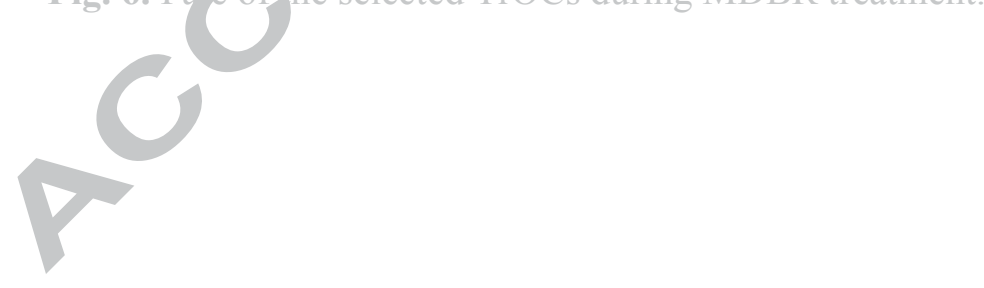




\section{LIST OF FIGURES}

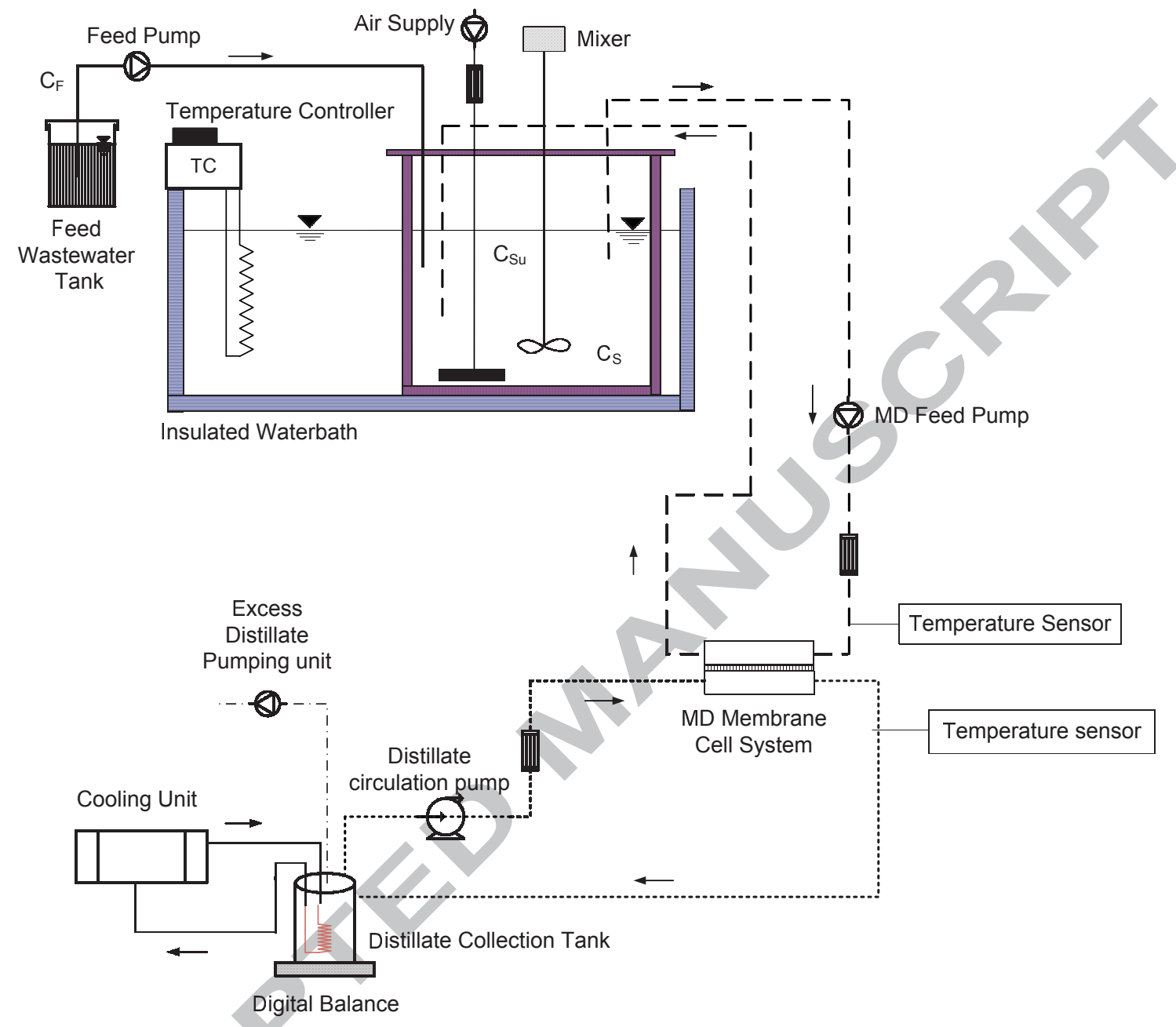

Fig. 1 


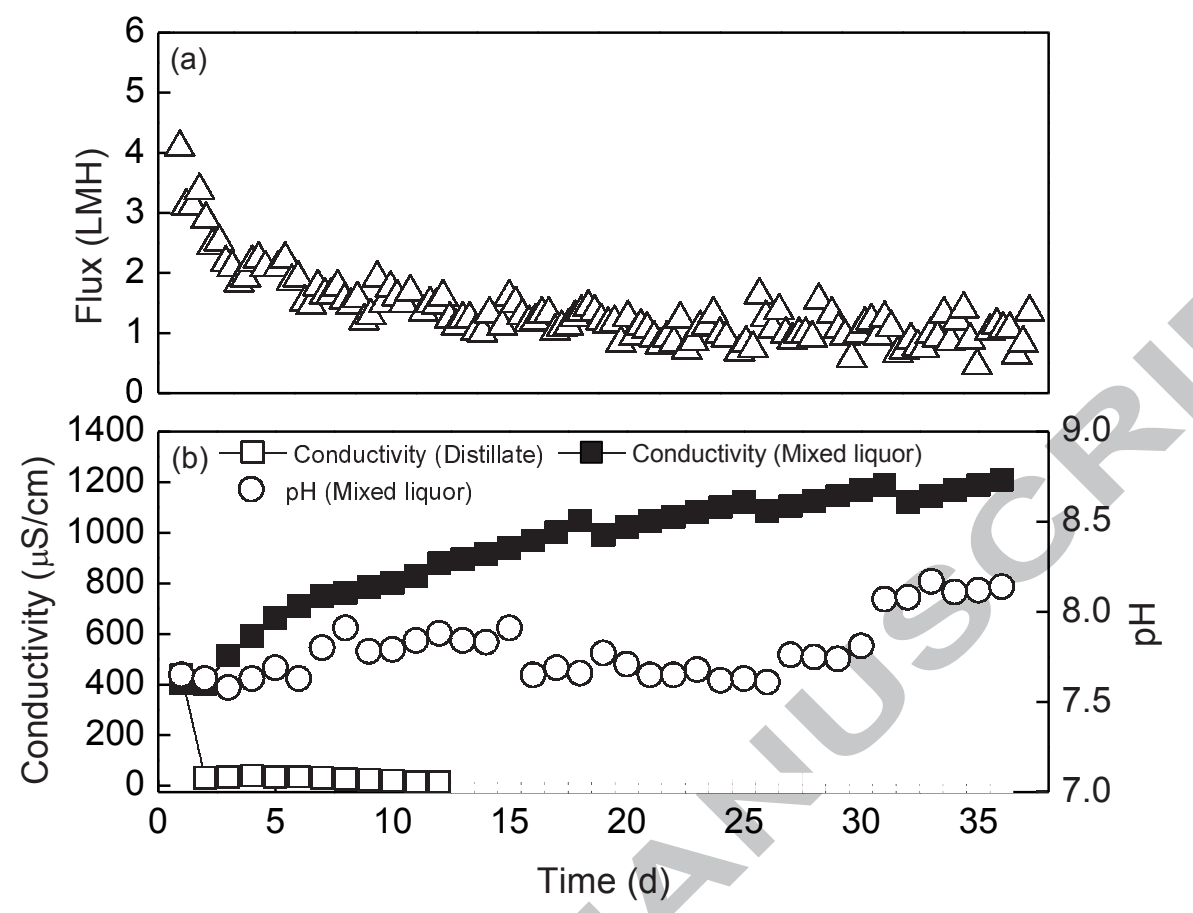

Fig. 2 


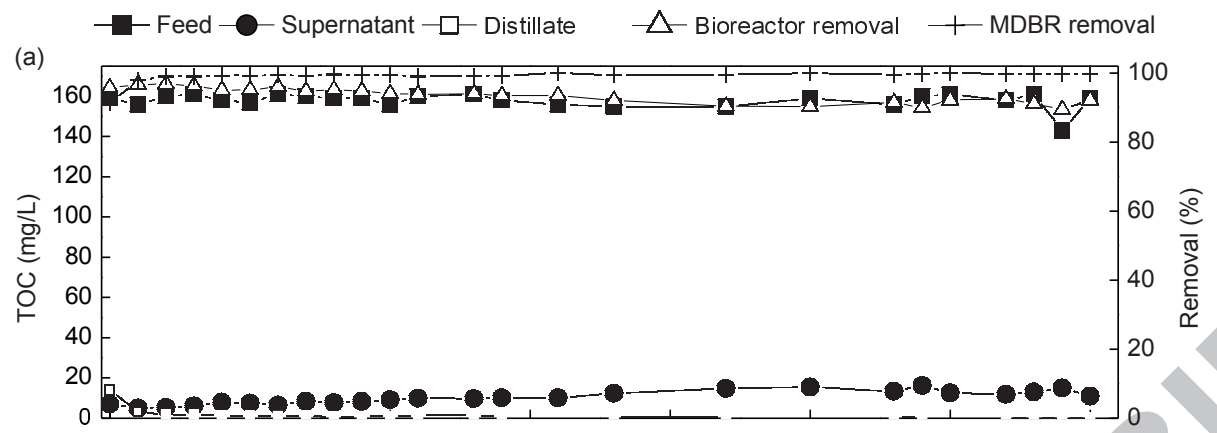

(b) $\checkmark$ Feed $\rightarrow$ Supernatant $\checkmark$ Distillate $\triangle$ Bioreactor removal + MDBR removal

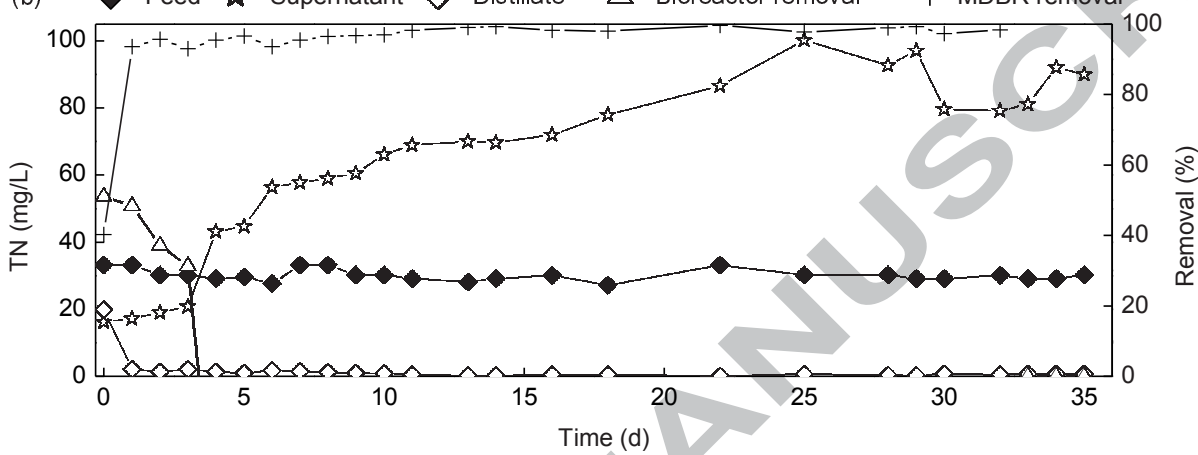

Fig. 3 


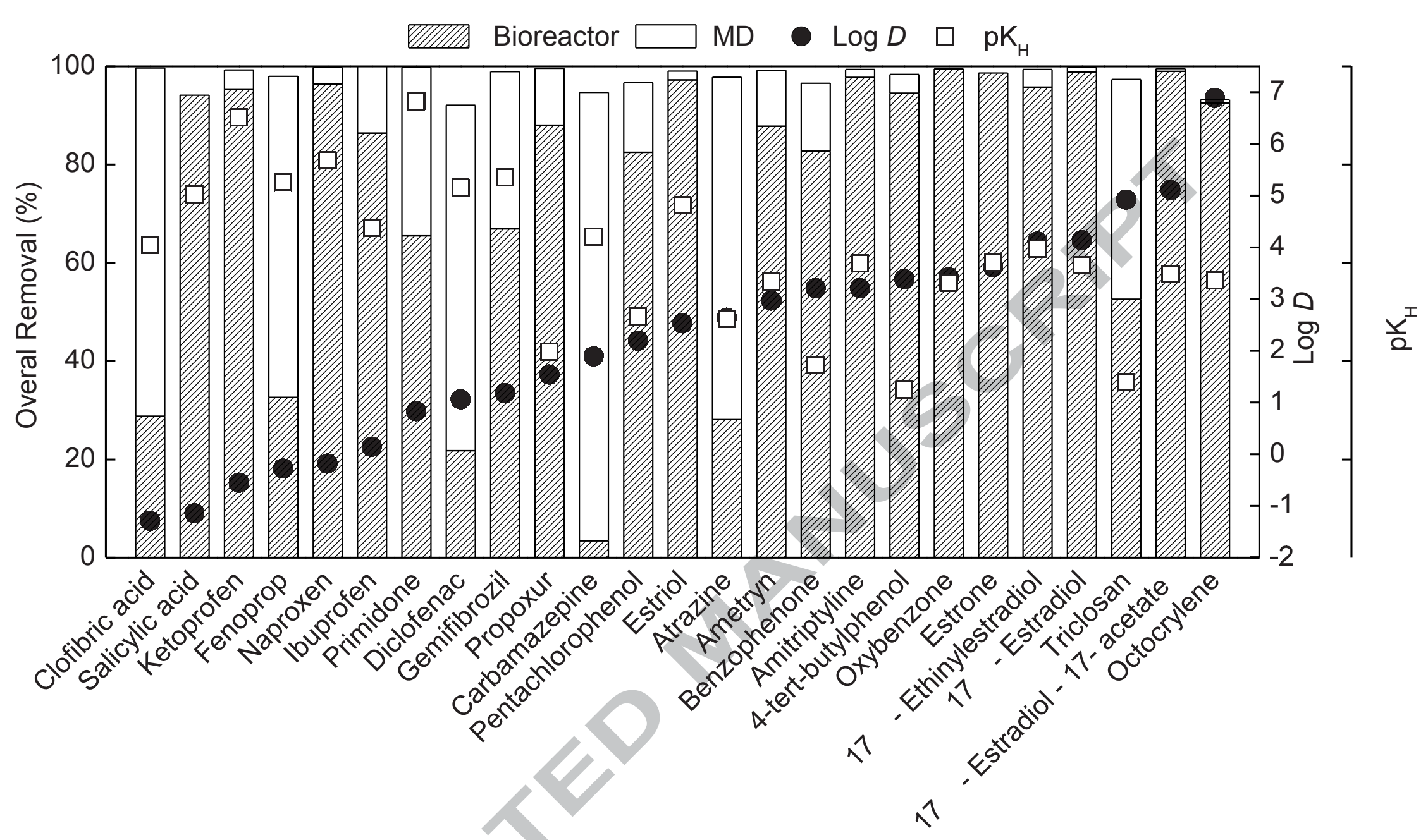




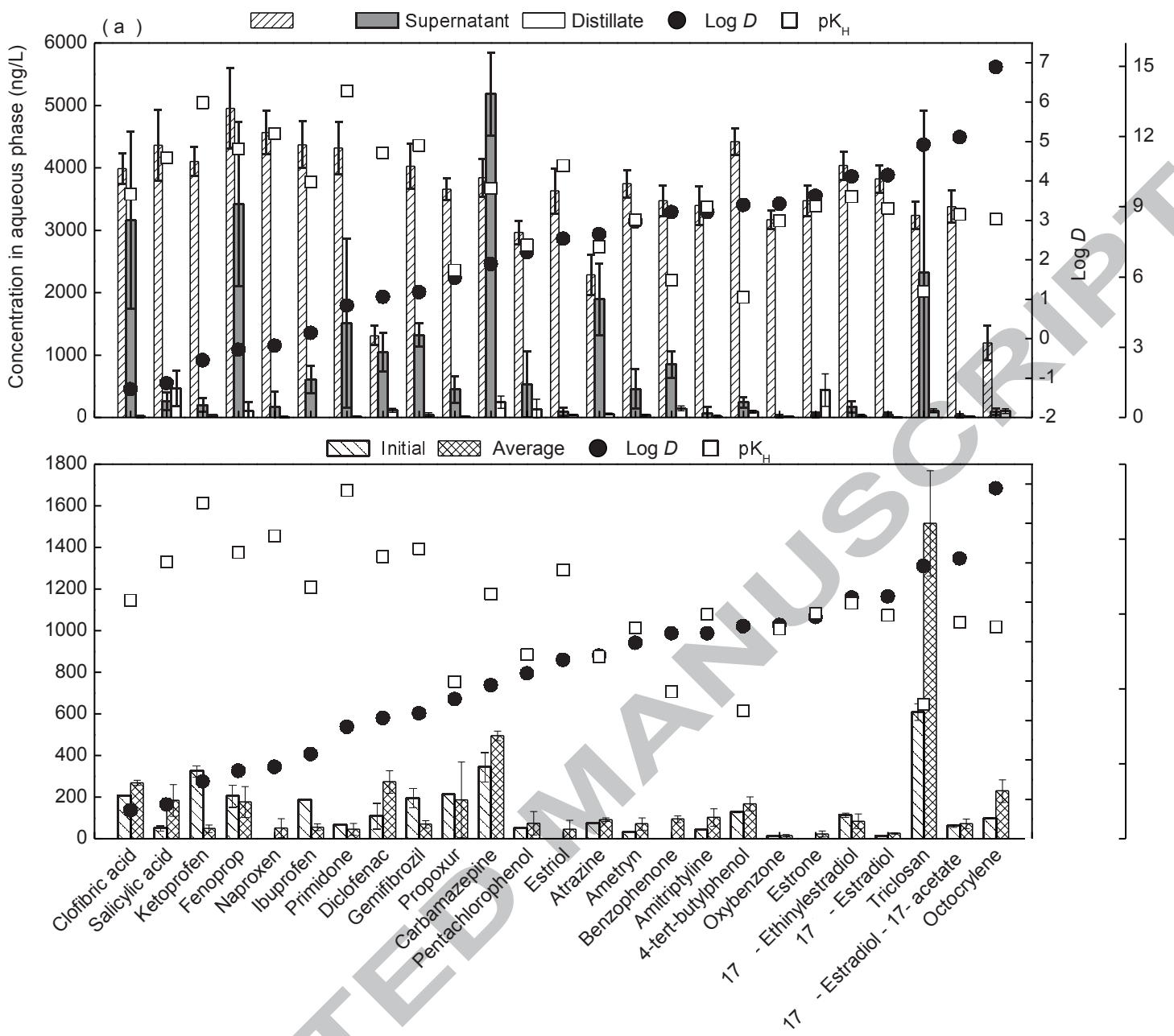


ช્å

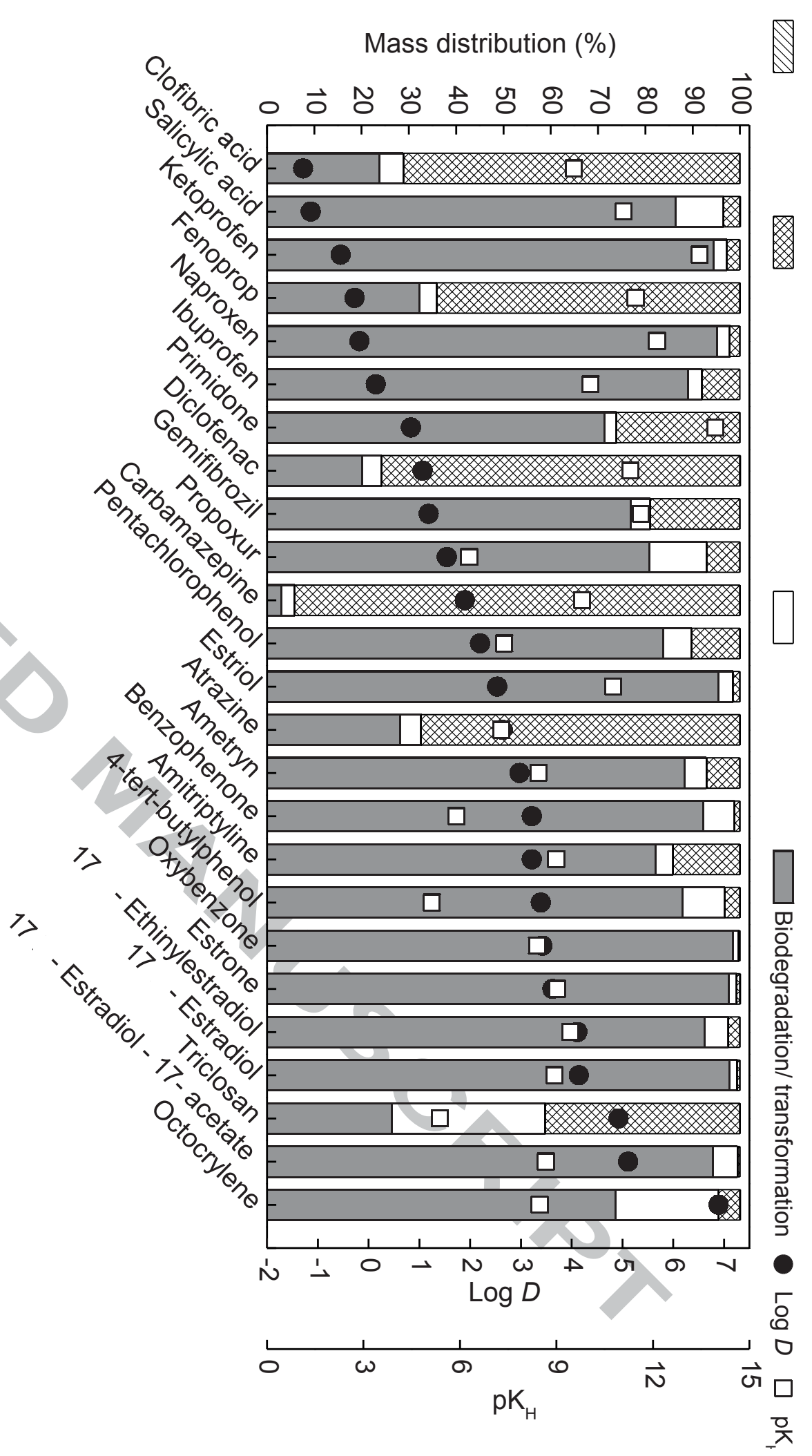


LIST OF TABLES

Table 1 Physicochemical properties of the selected compounds

\begin{tabular}{|c|c|c|c|c|}
\hline Compound & $\begin{array}{l}\text { Molecular } \\
\text { formula }\end{array}$ & $\begin{array}{l}\text { Molecular } \\
\text { Weight } \\
(\mathrm{g} / \mathrm{mol}) \\
\end{array}$ & $\begin{array}{c}\log D \\
\text { at pH } 8\end{array}$ & $\begin{array}{c}\text { pKK }_{\mathrm{H}} \text { at } \\
\text { pH } 8\end{array}$ \\
\hline Clofibric acid & $\mathrm{C}_{10} \mathrm{H}_{11} \mathrm{ClO}_{3}$ & 214.64 & -1.29 & 9.54 \\
\hline Salicylic acid & $\mathrm{C}_{7} \mathrm{H}_{6} \mathrm{O}_{3}$ & 138.12 & -1.14 & 11.09 \\
\hline Ketoprofen & $\mathrm{C}_{16} \mathrm{H}_{14} \mathrm{O}_{3}$ & 254.30 & -0.55 & 13.45 \\
\hline Fenoprop & $\mathrm{C}_{9} \mathrm{H}_{7} \mathrm{Cl}_{3} \mathrm{O}_{3}$ & 269.51 & -0.28 & 11.46 \\
\hline Naproxen & $\mathrm{C}_{14} \mathrm{H}_{14} \mathrm{O}_{3}$ & 230.30 & -0.18 & 12.12 \\
\hline Ibuprofen & $\mathrm{C}_{13} \mathrm{H}_{18} \mathrm{O}_{2}$ & 206.30 & 0.14 & 10.06 \\
\hline Primidone & $\mathrm{C}_{12} \mathrm{H}_{14} \mathrm{~N}_{2} \mathrm{O}_{2}$ & 218.25 & 0.83 & 13.93 \\
\hline Diclofenac & $\mathrm{C}_{14} \mathrm{H}_{11} \mathrm{Cl}_{2} \mathrm{NO}_{2}$ & 296.15 & 1.06 & 11.29 \\
\hline Gemfibrozil & $\mathrm{C}_{15} \mathrm{H}_{22} \mathrm{O}_{3}$ & 250.30 & 1.18 & 11.61 \\
\hline Propoxur & $\mathrm{C}_{11} \mathrm{H}_{15} \mathrm{NO}_{3}$ & 209.24 & 1.54 & 6.28 \\
\hline Carbamazepine & $\mathrm{C}_{15} \mathrm{H}_{12} \mathrm{~N}_{2} \mathrm{O}$ & 236.27 & 1.89 & 9.79 \\
\hline Pentachlorophenol & $\mathrm{C}_{6} \mathrm{HCl}_{5} \mathrm{O}$ & 266.38 & 2.19 & 7.37 \\
\hline Estriol & $\mathrm{C}_{18} \mathrm{H}_{24} \mathrm{O}_{3}$ & 288.40 & 2.53 & 10.76 \\
\hline Atrazine & $\mathrm{C}_{8} \mathrm{H}_{14} \mathrm{ClN}_{5}$ & 215.68 & 2.64 & 7.28 \\
\hline Ametryn & $\mathrm{C}_{9} \mathrm{H}_{17} \mathrm{~N}_{5} \mathrm{~S}$ & 227.33 & 2.97 & 8.43 \\
\hline Benzophenone & $\mathrm{C}_{13} \mathrm{H}_{10} \mathrm{O}$ & 182.22 & 3.21 & 5.88 \\
\hline Amitriptyline & $\mathrm{C}_{20} \mathrm{H}_{23} \mathrm{~N}$ & 277.40 & 3.21 & 8.99 \\
\hline 4 - tert - butyphenol & $\left(\mathrm{CH}_{3}\right)_{3} \mathrm{CC}_{6} \mathrm{H}_{4} \mathrm{OH}$ & 150.22 & 3.39 & 5.12 \\
\hline Oxybenzone & $\mathrm{C}_{14} \mathrm{H}_{12} \mathrm{O}_{3}$ & 228.24 & 3.42 & 8.39 \\
\hline Estrone & $\mathrm{C}_{18} \mathrm{H}_{22} \mathrm{O}_{2}$ & 270.36 & 3.62 & 9.20 \\
\hline $17 \alpha-$ Ethinylestradiol & $\mathrm{C}_{20} \mathrm{H}_{24} \mathrm{O}_{2}$ & 296.48 & 4.11 & 9.02 \\
\hline $17 \beta-$ Estradiol & $\mathrm{C}_{18} \mathrm{H}_{24} \mathrm{O}_{2}$ & 272.38 & 4.14 & 8.67 \\
\hline Triclosan & $\mathrm{C}_{12} \mathrm{H}_{7} \mathrm{Cl}_{3} \mathrm{O}_{2}$ & 287.50 & 4.92 & 5.37 \\
\hline $\begin{array}{l}17 \beta-\text { Estrodiol }-17- \\
\text { acetate }\end{array}$ & $\mathrm{C}_{20} \mathrm{H}_{26} \mathrm{O}_{3}$ & 314.42 & 5.11 & 8.67 \\
\hline Octocrylene & $\mathrm{C}_{24} \mathrm{H}_{27} \mathrm{~N}$ & 361.48 & 6.89 & 8.47 \\
\hline
\end{tabular}

Note: Henry's law constant $(\mathrm{H})$ values were calculated as: Henry's law constant at $25^{\circ} \mathrm{C}\left(\mathrm{atm} \cdot \mathrm{m}^{3} / \mathrm{mol}\right)=$ Vapour pressure $\times$ molecular weight $/$ water solubility. The $\mathrm{pK}_{\mathrm{H}}$ value is defined as $\mathrm{pK}_{\mathrm{H}}=-\log _{10} \mathrm{H}$. Molecular formulae, molecular weight, log $D$, vapour pressure and water solubility values were from SciFinder Scholar. 


\section{RESEARCH HIGHLIGHTS}

- Salinity build-up occurred during MDBR

- Salinity build-up could affect TN and TrOC removal by the bioreactor

- However, MDBR achieved high performance regarding all water quality parame

- Biodegradation governed the removal of most TrOCs by the bioreactor

- Physical separation by MD governed the removal of recalcitrant TrOCs

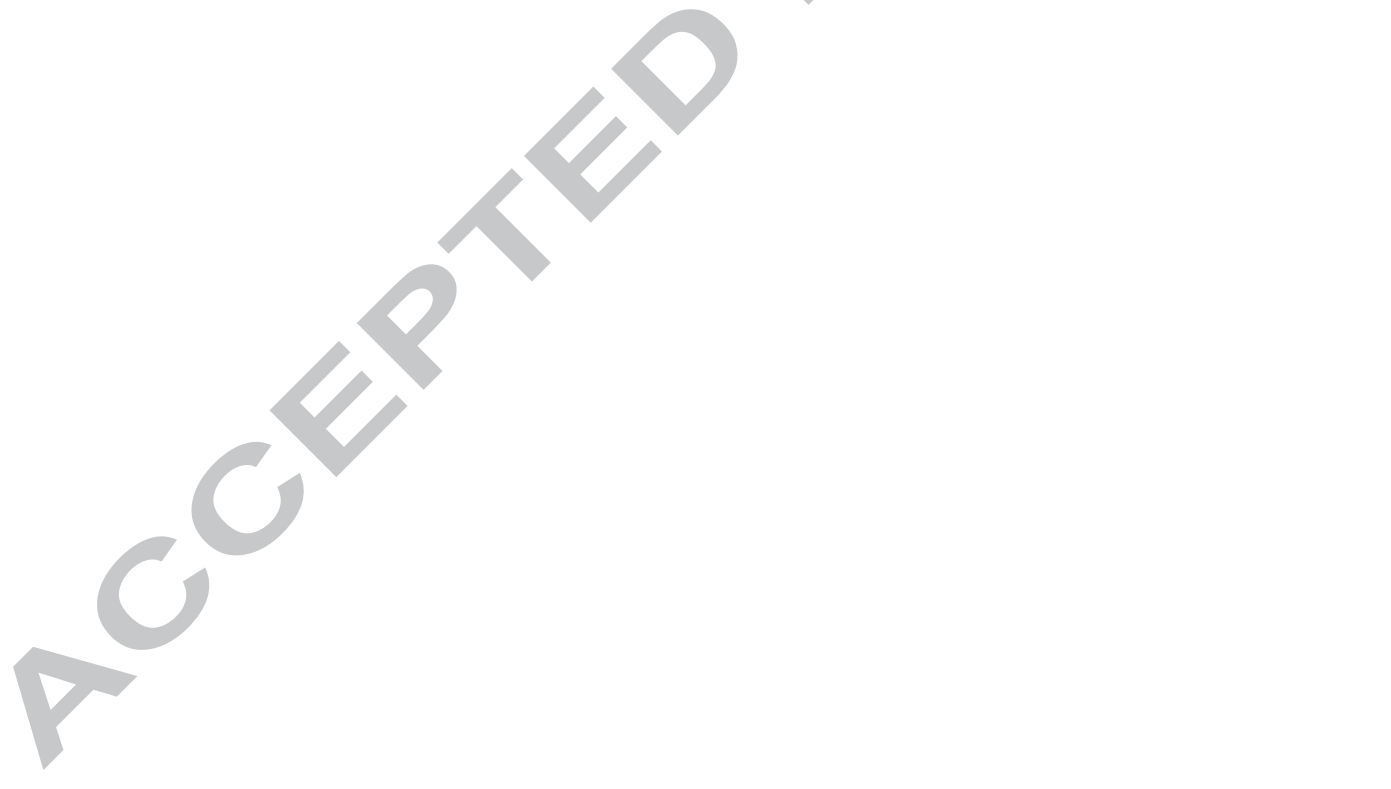

